Rayia J Al-Naimi BDS, MSc (Asst Prof.)

\section{Effect of at Home Dental Bleaching and the Use of Antioxidant on Microleakege of Fis- sure Sealant: An in Vitro Study}

Dept of Pedod, orthod, and Prev Dentistry

College of Dentistry, University of Mosul

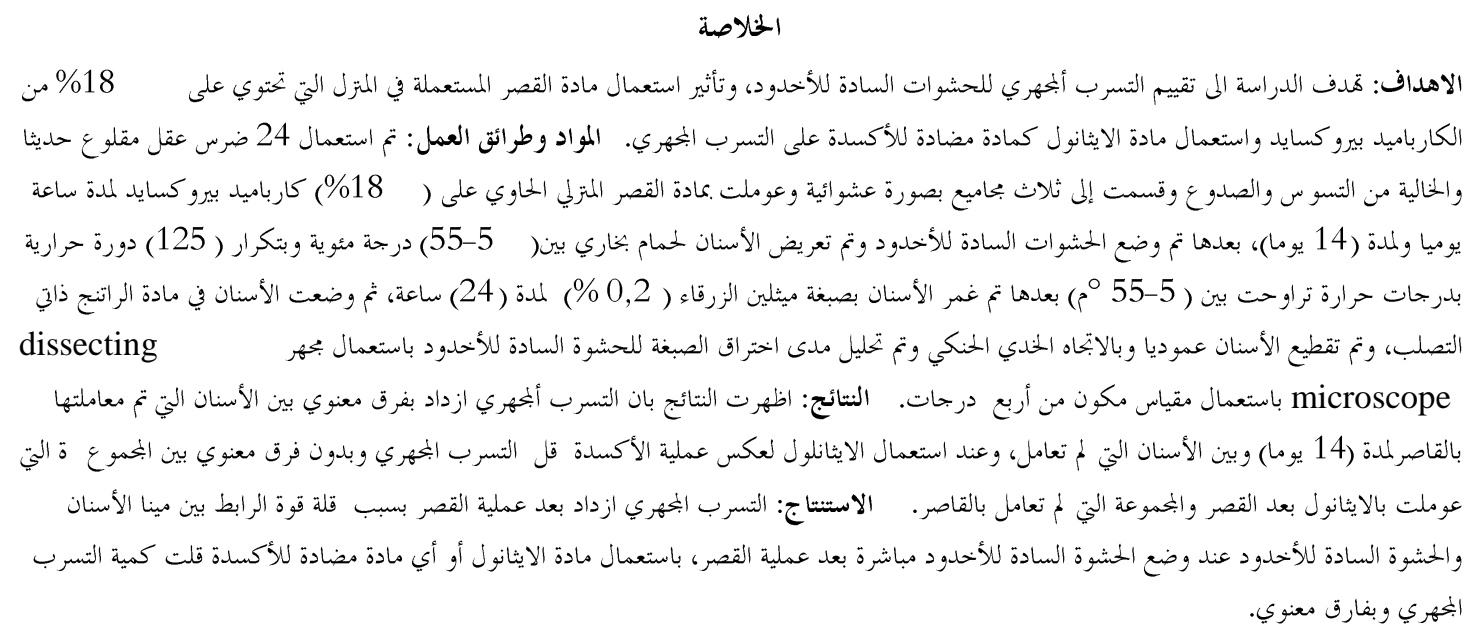

\begin{abstract}
Aim of the study: To evaluate in vitro the microleakage of fissure sealant, the effect of using home bleaching agent containing $18 \%$ carbamide peroxide and the effect of ethanol as an antioxidant agent on microleakage. Materials and Methods: Twenty four extracted sound human third molars were randomly assigned to 3 groups. After sealant placement, the teeth were thermocycled (125 cycles; 5 $55^{\circ} \mathrm{C}$ ), isolated, immersed in $0.2 \%$ methylene blue dye for 24 hours, included in acrylic resin and sectioned longitudinally in a buccolingual direction. The sections were analyzed for leakage using an stereomicroscope, and a 4-criteria ranked scale was used to score dye penetration. Results: Microleakage scores increased with significant difference between control and bleached group when home bleach was used for fourteen days, also leakage scores decreased with significant difference when ethanol was used after bleaching to reverse the oxidation process, no significant difference was observed between control versus ethanol group. Conclusions: Microleakage scores increased after bleaching because of reduction in enamel bond strength of sealant when the bonding procedure was carried out immediately after bleaching, use of ethanol or other types of antioxidant reduced the amount of microleakage significantly.
\end{abstract}

Key Words: Home bleach ,microleakage, fissure sealant, antioxidant

Al-Naimi RJ. Effect of at Home Dental Bleaching and the Use of Antioxidant on Microleakege of Fissure Sealant : An in Vitro Study. Al-Rafidain Dent J. 2012; 12(1): 102-108.

Received: $12 / 5 / 2010$

Sent to Referees: $16 / 5 / 2010$

Accepted for Publication: 21/11/2010

\section{INTRODUCTION}

Significant progress has been made in the prevention of dental caries in children and adolescents over the past thirty years. While caries is decreasing on interproximal surfaces, occlusal pit and fissure caries continue to increase. ${ }^{(1,2)}$ Pit and fissure sealants are considered an outstanding adjunct to oral health care strategies and fluoride therapy in decreasing occlusal caries onset and/or progression. ${ }^{(3,4)}$
Bleaching of teeth has had a renewed interest since the first 1989 publication of the technique originally called Nightguard vital bleaching. ${ }^{(5)}$ This technique applies a $10 \%$ carbamide peroxide or slightly higher concentrations applied in a custom-fitted tray for a number of days or weeks, preferably using overnight wear. Early reports cite the use on children as young as 10 years of age, primarily for brown fluorosis or genetically yellow permanent teeth. ${ }^{(6)}$ 
Many studies have shown a considerable reduction in enamel bond strength of resin composite restorations when the bonding procedure is carried out immediately after bleaching. These studies claim that a certain waiting period is needed prior to the restoration to reach the original bond strength values prior to bleaching. ${ }^{(7)}$

It is recommended, delays in bonding of 1 to 3 weeks following the bleaching procedure for the enamel to return to the conditions that lead to normal bond. The lower bond strengths of bleached enamel and dentin are a result of the oxidative process caused by the bleaching agents. $^{(8-11)}$ Some authors assert that the oxygen remains in the dental structure after bleaching and can interfere with the polymerization of adhesive monomers. ${ }^{(11)}$ Nevertheless, it was observed that the use of anti-oxidant agents before the bonding process can reverse the compromised bonding to bleached enamel. ${ }^{(11,12)}$

The present study was therefore designed to evaluate the effect of at home dental bleaching on microleakage of one type of fissure sealant, and the effect of the use of ethanol as an antioxidant agent.

\section{MATERIALS AND METHODS}

Twenty four extracted human third molars free of cracks, caries and restorations were selected, cleaned with periodontal curettes and stored in distilled water with thymol at room temperature. The occlusal surface of the teeth was then polished with non-fluoridated pumice (Qualy Dental,England) with rubber cups (Products Dentaires, Switzerland) at slow speed. The teeth were randomly assigned to 3 groups $(n=8)$. No invasive technique (enameloplasty) was used prior to sealant placement. Conseal $\mathrm{f}$ fluoride releasing light cured sealant that contains $7 \%$ filler particles filled with a submicron filler size of 0.04 microns to withstand surface wear was used in all 3 groups (Helioseal F, Southern Dental Industries). For first group, the sealant material was applied immediately on the occlusal surfaces of the teeth After acid etching with 37\% phosphoric acid (Super etch, Southern Dental Industries) for 20 seconds, washed for 5 seconds and dried with oil-free com- pressed air, sealing material was applied to the pits and fissures along their entire extension with an disposable brush (Southern Dental Industries) and cured for 20 seconds with an LED light curing unit $1800 \mathrm{~mW} / \mathrm{cm}^{2}$ (Apoza /Taiwan ).

For the two other groups, the home bleaching solution that contained $18 \%$ carbamide peroxide (Hellerdent Easy \& White ${ }^{\mathrm{TM}}$ ) was applied on the occlusal surfaces of the teeth for 60 minutes, then was rinsed thoroughly with water spray, the teeth were kept in distilled water until the next bleaching session. This process was repeated daily for a period of fourteen days consequently (according to the manufacturer instructions). After bleaching, for the second group, the fissure sealant was applied immediately after the last bleaching session according to the manufacture instruction as in the first group, while for the final group, ethanol (Gainland Chemical Company UK), an antioxidant was applied to the occlusal surface for 20 minutes with a cotton pellet immediately after bleaching, the surfaces were kept moist with ethanol and wetted constantly because of the evaporation of ethanol, then they were rinsed with tap water for 30 seconds and then air dried for 20 seconds ${ }^{(13)}$ then the sealants were applied to the last group.

In preparation for dye penetration test, the root apexes were sealed with acrylic resin, and all the teeth except occlusal surface were coated with two layers of clear nail polish (Turkey).

The teeth were subjected to thermocycling for 125 cycles at temperatures of $5^{\circ} \mathrm{C} \pm 2{ }^{\circ} \mathrm{C}$ and $50^{\circ} \mathrm{C} \pm 2{ }^{\circ} \mathrm{C}$ with a dwell time of 15 seconds. ${ }^{(14)}$ This was followed by the immersion of the teeth in $0.2 \%$ methylene blue dye for 24 hours. ${ }^{(15)}$

After removal from the dye solution, they were cleaned and rinsed with tap water. The teeth were embedded in selfcuring acrylic resin to prevent chipping of the material and the resin blocks were sectioned with a cut buccolingually and parallel to the long axis, into two fragments using diamond disk for sectioning (Germany). After the above procedures, the length of dye penetration at the sealant/tooth interface was examined under a dissecting microscope with $40 \times$ magni- 
fication (Altay, Italy ).

The criteria for the amount of dye microleakege was the level of maximum dye penetration. Grading of microleakage was based on the following criteria: ${ }^{(16)}$

Grade $0=$ No penetration, ( Figure 1).

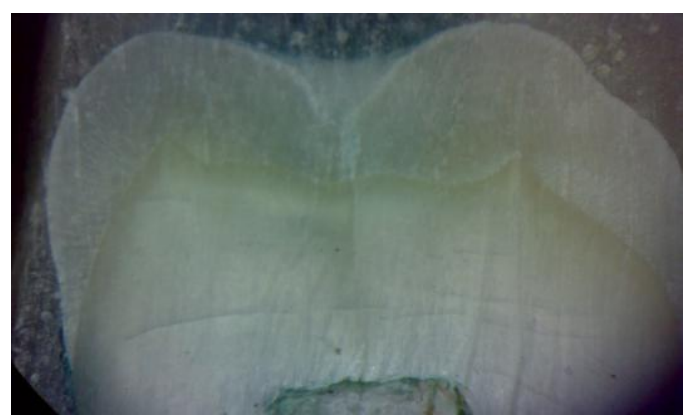

Figure (1): Score 0

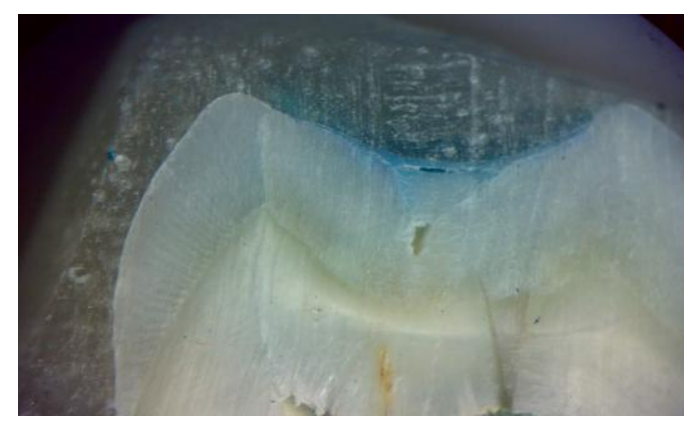

Figure (3): Score 2

The data were analyzed using Kruskal -Wallis, Mann-Whitney U non-parametric tests to compare the groups for statistically significant differences at $0.5 \%$ significance level.

\section{RESULTS}

No sealant was lost. Microleakage scores are shown in Table (1). Most teeth in the control group did not show dye penetration (score 0 ), with no tooth scoring (3).

In the bleached group, only one tooth exhibited score zero, and most of the sample showed score 2 (three teeth) and score 3 found in 2 teeth, while in the group that was treated with ethanol prior to fissure sealing the majority of the sample showed score 1 .
Grade $1=$ dye penetration limited to the outer half of the sealant, (Figure 2).

Grade $2=$ dye penetration extending to the inner half of the sealant, (Figure 3).

Grade 3= dye penetration extending to the underlying fissure, (Figure 4).

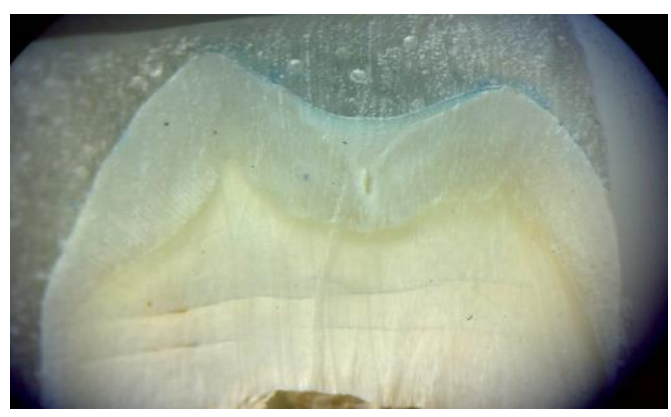

Figure (2): Score 1

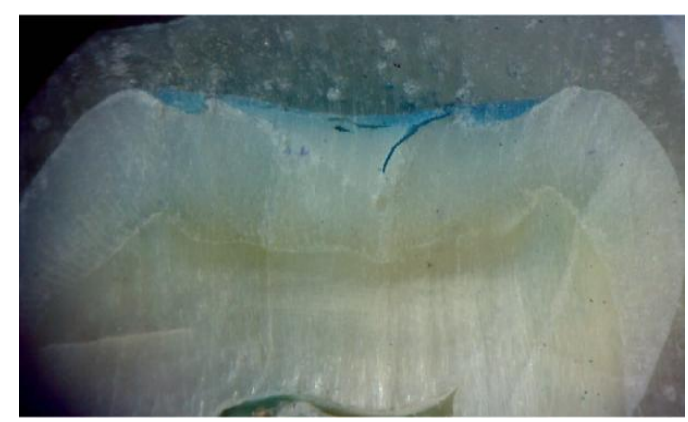

Figure (4): Score 3

Table (1): Distribution of Microleakage Scores according to Groups.

\begin{tabular}{|c|c|c|}
\hline Group & Criteria & Frequency \\
\hline \multirow{4}{*}{ Control } & 0 & 5 \\
\hline & 1 & 2 \\
\hline & 2 & 1 \\
\hline & 3 & 0 \\
\hline \multicolumn{2}{|c|}{ Total } & 8 \\
\hline \multirow{4}{*}{ Bleached } & 0 & 1 \\
\hline & 1 & 2 \\
\hline & 2 & 3 \\
\hline & 3 & 2 \\
\hline \multicolumn{2}{|c|}{ Total } & 8 \\
\hline \multirow{4}{*}{ Ethanol } & 0 & 2 \\
\hline & 1 & 5 \\
\hline & 2 & 1 \\
\hline & 3 & 0 \\
\hline \multicolumn{2}{|c|}{ Total } & 8 \\
\hline
\end{tabular}


It can be observed in Table (2) that there was statistically significant difference in leakage scores for all the three groups with $P<0.05$, while Table (3) demonstrates leakage scores between each two groups at a time. There was a statisti- cally significant difference in leakage in the control versus the bleached group, and the bleached versus ethanol group, with no significant difference between control versus ethanol group.

Table (2): Comparison of microleakage scores for the three groups.

$\begin{array}{ccc}\text { Chi-Square } & \text { Degree of Freedom } & P \text {-Value } \\ 6.746 & 2 & 0.034\end{array}$

Kruskal-Wallis test

Table (3): Comparison of microleakage scores between groups.

\begin{tabular}{ccc} 
Groups & Z value & P Value \\
Control Vs Bleached & 2.302 & $0.02(\mathrm{~S})$ \\
Bleached Vs Ethanol & 1.831 & $0.05(\mathrm{~S})$ \\
Control Vs Ethanol & 1.208 & $0.22(\mathrm{NS})$ \\
\hline
\end{tabular}

Mann-Whitney U test

Figure (5) displays the percentages of the microleakage scores obtained in this study. In control group, $62.5 \%$ of the sample showed no leakage, while $25 \%$ showed score 1 , while score 2 was the maximum score that was found in $12.5 \%$. In the bleached group, score 0 was much reduced ( only $12.5 \%$ ), score 1 was observed in
$25 \%$, score 2 was found in majority $(37.5 \%)$, and score 3 found in $25 \%$. In the ethanol group, there was a slight increase in score 0 compared with bleached group, majority exhibited score $1(62.5 \%)$, while score 3 was found in only $12.5 \%$ of the group.

\section{$\square 0 \square_{1} \square_{2} \mathbf{\square}_{3}$}

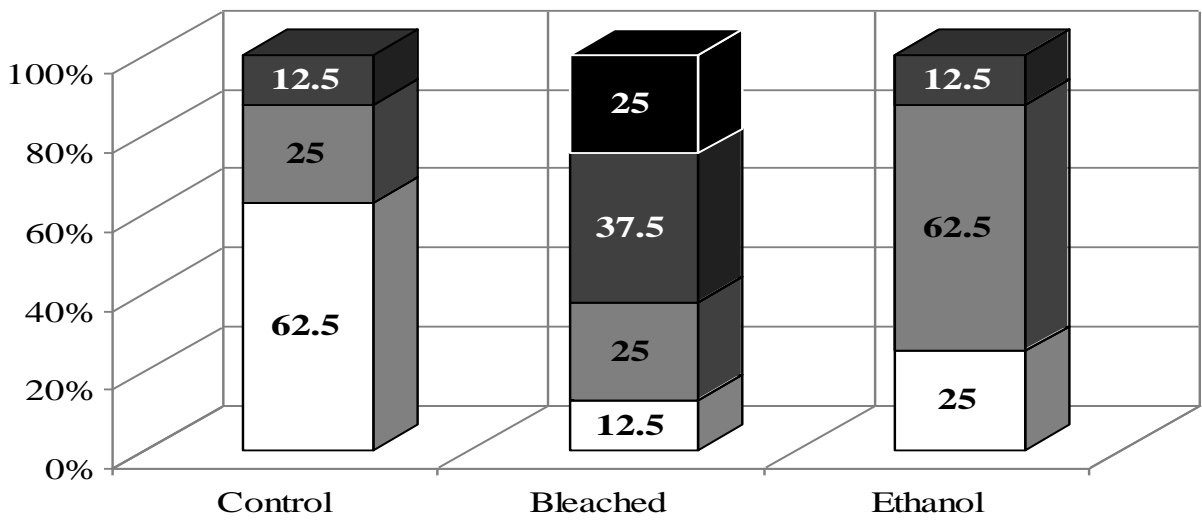

Figure (5): Percentage of microleakage scores.

\section{DISSCUSSION}

Pit-and-fissure sealants have been considered an outstanding adjunct to oral health care preventive strategies in decreasing occlusal caries onset and/or pro- gression. ${ }^{(17)}$ The properties of an ideal sealing material include biocompatibility, retention and resistance to abrasion and wear. ${ }^{(18)}$ Sealant bonding to enamel is also important because microleakage at tooth- 
material interface can lead to treatment failure.

Microleakage is defined as the passage of bacteria, fluids, molecules, and ions between the teeth and the sealing material. ${ }^{(19)}$ Since this condition may shorten the longevity of any restoration, it should be minimized or preferably eliminated. ${ }^{(20)}$

There have been many methods to assess the sealing ability of pit and fissure sealants, the most common approach is the measurement of dye penetration along the interface, In some of these studies methylene blue was employed as tracer to evaluate the degree of infiltration. The small particle size and the permeability of dentinal tubules may lead to overestimate the relevance of this infiltration. ${ }^{(21)}$ The area of methylene blue is calculated to be around $0.52 \mathrm{~nm}$, smaller than average bacteria. As bacteria have a diameter of 0.3-1.5 $\mu \mathrm{m}$ or larger. This technique cannot distinguish between too narrow and sufficiently wide gaps to allow bacteria passage. An interesting finding was that the use of methylene blue tracer leads to higher leakage scores than other microscope evaluations. ${ }^{(22)}$

The present study showed that exposure of human teeth to at home bleaching material that contained $18 \%$ carbamide peroxide for 1 hour daily for two weeks produces a significant increase in micorleakage of fissure sealant whenever placed immediately after bleaching Tables (1) and (2). The bleached group during microscopic examination showed extensive dye penetration at their seals compared with control group, this result principally from an inability of the sealant material to adhere properly to the etched enamel surface due to decrease in enamel bond. This is in agreement with the results of other studies on composite resins, ${ }^{(23,24)}$ that found the bonding strength decreased after use of carbamide peroxide, which may be attributed to weak bonding surfaces that are related to enamel surface morphology with varying degrees of surface roughness and structural changes due to loss of prismatic formation ,another explanation is that the substance and microhardness of the tooth may be affected by the bleaching procedure. Another cause increasing microleakage after bleaching, may be attributed to the reason that reminants of residual oxygen in the tooth structer may interact with the polymerization of the fissure sealant resulting in poor adaptation and sealing to the tooth structure. ${ }^{(25)}$

No previous study has been performed studying the effect of home bleach on fissure sealants to compare results of this study with, home bleach has undergone dramatic improvements since it began to be used. ${ }^{(26)}$ By increasing the concentrations of bleaching agents, the time the bleaching trays are kept in the patients mouth has been reduced from full night to less hours.

According to a study on compsite resins, ${ }^{(25)}$ residual oxygen, which is released from the bleaching agent as the nascent oxygen and hydroxyl or peri-hydroxyl ions when they were applied to the dental structure, interfered with the resin infiltration into the etched enamel or inhibited the polymerization of resin, the same possibility exist in case of sealant.

Table (3) shows that there was a statistically significant difference in scores leakage. Increased micrleakage scores could be attributed to retained peroxide in the subsurface layer of the enamel possibly resulting in gaseous bubbling from oxidizing reactions that leads to porous formation in the interfaces. ${ }^{(12)}$

When the teeth were treated with ethanol which is an antioxidant agent after bleaching and before performing the sealing with the fissure sealant there was a reduction in the microleakage scores with a statistically significant difference compared with the bleached group $P \leq 0.05$ (Figure 5), which might be attributed to the reason that the ethanol contained as solvent, may have minimized and/or reversed the inhibitory effect of hydrogen peroxide on resin polymerization, removing residual oxygen by-products thanks to its water-chasing action. A similar mechanism has been described in studies on compromised bonding to bleached enamel. ${ }^{(27)}$

The antioxidant role in reversing hydrogen peroxide-related adverse effects on resin bond requires additional research. 


\section{CONCLUSIONS}

Results showed that applying the sealant immediately after bleaching resulted in a significant difference in increasing microleakage, so if a dental operator is planning to apply fissure sealants to a person using home bleaching products, it is recommended to delay sealant application for a period of 1 to 3 weeks following the bleaching procedure for the enamel to return to the conditions that lead to normal bond or to use an antioxidant agent, as the scores decreased with significant difference when ethanol was used after bleaching and before applying fissure sealants. Other studies are further needed to determine the effect of other types of antioxidant agents such as sodium bicarbonate, sodium ascorbate on microleakage of fissure sealants.

\section{REFERENCES}

1. Eccles MFW. The problem of occlusal caries and its current management. New Zealand Dent J. 1989; 85(380): 50-55.

2. Kutesa A, Mwanika A, Wandera M. Pattern of dental caries in Mulago dental school clinic Uganda. Afr Health Sci. 2005; 5(1): 65-68.

3. Ripa LW. Sealants revisited: An update of the effectiveness of pit-and fissure sealants. Caries Res. 1993; 27(1): 77-82.

4. Shaw L. Modern thoughts on fissure sealants. Dent Update. 2000; 27: 370374.

5. Haywood VB, Heymann HO. Nightguard vital bleaching. Quintessence Int. 1989; 20:173-176.

6. Haywood VB. History, safety, and effectiveness of current bleaching techniques and applications of the nightguard vital bleaching technique. Quintessence Int. 1992. 23:471-488.

7. Kaya AD, Turkun M. Reversal of dentin bonding to bleached teeth. J Oper Dent. 2003; 28(6): 825-829.

8. Rotstein I. Role of catalase in the elimination of residual hydrogen peroxide following tooth bleaching. $J$ Endod. 1993; 19: 567-569.

9. Barghi N, Godwin JM. Reducing the adverse effect of bleaching on compo- site-enamel bond. J Esthet Dent. 1994; 6: $157-161$.

10. Lai SC, Mak VF, Cheung GS, Osorio R, Toledano M, Carvalho RM. Reversal of compromised bonding to oxidized etched dentin. J Dent Res. 2001; 80: 1919-1924.

11. Lai SC, Tay FR, Cheung GS, Mak VF, Carvalho RM, Wei SH et al. Reversal of Compromised Bonding in Bleached Enamel. J Dent Res. 2002; 81: 477481.

12. Turkun M, Kaya A.D. Effect of $10 \%$ sodium ascorbate on the shear bond strength of composite resin to bleached bovine enamel. J Oral Rehabil. 2004; 31: 1184-1191.

13. Torris CRG,Koga AF and Borges AB. The effects of antioxidant agents as neutralizers of bleaching agents on enamel bond strength. Braz J Oral Sci. 2006; 5(16): 971-975.

14. Ashwin RA, Arathi RB. Comparative evaluation for microleakage between Fuji-VП glass ionomer cement and light-cured unfilled resin: A combined in vivo in vitro study. $J$ Indian Soc Pedod Prev Dent. 2007; 25(2): 86-87.

15. Yavyz I and Aydin H. A new method: measurement of microleakage volume using human, dog and bovine permanent teeth. Elect J Biotech. 2006; 9(1): 8-17.

16. Zervou C, Kugel G, Leone C, Zavras A, Doherty EH, White GE. Enameloplasty effects on microleakage of pit and fissure sealants under load: an in vitro study. J Clin Pediatr Dent. 2000; 24: 279-285.

17. Simonsen RJ. Pit and fissure sealant: review of the literature. Pediatr Dent 2002; 24: 393-414.

18. Pérez-Lajarin L, Cortés-Lillo O, García-Ballesta C, Cózar Hidalgo A. Marginal microleakage of two fissure sealants: a comparative study. J Dent Child. 2003; 70:24-28.

19. Hidalgo AC, Lajarin L p, Lillo OC, Ballesta CG. Marginal microleakage of two fissure sealants: A Comparative study. J Dent Child. 2003; 70: 24- 28.

20. Sobia PA, Pimenta LAF, Ambrosano GMB. Effect of collagen removal on microleakege of resin composite restorations. J Oper Dent. 2002; 27; 38-43. 
21. Gale MS, Darvell BW. Thermal cycling procedures for laboratory testing of dental restorations. J Dent. 1999; 27: 105-108.

22. Almeida JB, Platt JA, Oshida Y, Moore BK, Cochran MA, Ekert GJ. Three different methods to evaluate microleakage of packable composites in class II restorations. J Oper Dent. 2003; 28: 453-460.

23. Josey AL, Meyers IA, Romaniuk K, Symons AL. The effect of a vital bleaching technique on enamel surface morphology and the bonding of composite resin to enamel. J Oral Rehab. 1996; 23; 244-250.

24. Cavalli V, Arrais M, Giannini G. High concentrated carbamide peroxide bleaching agents effect on enamel sur- face. J Oral Rehab. 2004; 31(2); 155 159.

25. Sundfeld RH, Briso AL, De Sa PM, Sundfeld ML, Bedran -Russo AK. Effect of time interval between bleaching and bonding on tag formation. Bull Tokyo Dent Coll . 2005; 46; 1-6.

26. Donly KJ, Donly AS ,Baharloo L, Rojas-Candelas E, Zhou X ,Gerlach RW. Tooth Whitening in Children. Compendium.2002; 23(1): 22-28.

27. Kum KY, Lim KR, Lee CY, Park KH, Safavi KE, Fouad AF, Spangberg LS. Effects of removing residual peroxide and other oxygen radicals on the shear bond strength and failure modes at resin-tooth interface after tooth bleaching. Am J Dent. 2004; 17: 267-270. 